\title{
Improving drought resilience in Northern Murray-Darling Basin farming communities: Is forecast-based financing suitable?
}

\author{
Atifa Asghari ${ }^{1,2}$ - Yuriy Kuleshov ${ }^{2,3,4}$ (D) Andrew B. Watkins ${ }^{2}$. Jessica Bhardwaj ${ }^{1,2}$. \\ Isabella Aitkenhead ${ }^{1,2}$
}

Received: 16 September 2020 / Accepted: 15 June 2021 / Published online: 17 August 2021

(c) Crown 2021

\begin{abstract}
A trend towards drier conditions during the April to October 'cool' season across southern Australia has been observed in the past few decades. Frequent and prolonged droughts have a significant impact on the financial stability of affected farming communities. Forecastbased Financing $(\mathrm{FbF})$ is a novel proactive aid approach that provides support measures to increase resilience during the window between drought early warnings, and the actual onset and intensification of drought. Using the Northern Murray-Darling Basin as a case study, we investigated whether FbF combined with a user-centred Integrated Early Warning System (I-EWS) for drought has the potential to increase the drought resilience of Australian farming communities. This study shows that farming businesses most impacted by drought have three common factors: (i) lower levels of business management skills, (ii) lower levels of pre-drought preparedness during non-drought periods, and (iii) slower responses when the intensity of drought increases. The results suggest that FbF in its current form is not recommended for a market economy such as Australia, as forms of direct assistance may have adverse long-term effects through disrupting the market itself and may not encourage farm operators to regularly assess and adapt their drought management strategies. Results also suggest that providing farmers, service providers, and all levels of government with tools that incorporate a user-centred I-EWS for drought can improve overall decision-making before, during, and even after drought. This change from a reactive to a proactive approach to managing drought impacts can be a highly effective form of increasing the drought resilience of farming communities.
\end{abstract}

Keywords Drought resilience $\cdot$ Australia $\cdot$ Murray-Darling Basin $\cdot$ Forecast-based financing $\cdot$ Proactive assistance $\cdot$ User-centred integrated early warning system for drought $\cdot$ Climate risk

Yuriy Kuleshov

yuriy.kuleshov@bom.gov.au

1 Monash University, Clayton, Victoria, Australia

2 Bureau of Meteorology, Docklands, Victoria, Australia

3 Royal Melbourne Institute of Technology (RMIT) University, Melbourne, Victoria, Australia

4 The University of Melbourne, Parkville, Victoria, Australia 


\section{Introduction}

Natural rainfall variability in Australia is large and strongly influenced by global climate drivers such as the El Niño-Southern Oscillation and the Indian Ocean Dipole. However, in recent decades, there has emerged a trend towards drier conditions across southern Australia (Bureau of Meteorology and CSIRO 2018). In the southwest of Australia, there has been a steady decline in April to October rainfall, with the largest decrease observed in May to July rainfall of around $20 \%$ from the 1970s. In the southeast of Australia, April to October rainfall has decreased by around 11\% from the late 1990s. The prolonged dry conditions in the southwest and southeast of Australia had detrimental impact on operations of many farming communities.

Drought in Australia refers to an acute water shortage across the landscape that affects vegetation growth, river flows, water storages, and ultimately communities. Droughts depend on the local rainfall climatology, soil types, evaporation rates, and runoff, which in themselves have differing driving factors (Mishra and Singh 2010). This complexity of impacts and drivers means that no universal definition of drought exists, as there are various types and context-specific nuances (Lloyd-Hughes 2013). Ultimately, drought types can be better understood by looking at how they impact people, the environment, and the economy. These include meteorological, agricultural, socio-economic, and hydrological impacts, which have differences in spatial extent and time periods (Hennessy et al. 2008; Wilhite et al. 2014). A farmer, for example, is concerned with insufficient water availability during a season for crops, pastures, and stock. All these factors make defining and hence adapting and mitigating drought impacts a difficult, but critical, task. In this study, we are focused on drought impacts on agriculture sector.

The Murray-Darling Basin (MDB) covers 14\% of Australia but accounts for almost $40 \%$ by value of Australia's agricultural production, producing on average 22 billion AUD worth of agricultural commodities each year (Murray-Darling Basin Authority 2019) and containing $40 \%$ of all farms in Australia (Australian Bureau of Statistics et al. 2009). It is also one of Australia's most drought-prone areas, due to its geographic location and the area's sensitivity to climate variability (Crimp, 2010; Kiem 2013).

Frequent and prolonged droughts have a significant impact on the financial stability of rural and regional businesses in the MDB due to reduced property outputs (Edwards et al. 2009). Farmers are required to be very adaptable in managing their farms due to frequent changes in water availability, global commodity prices, and a rapidly changing farming industry (Edwards et al. 2008; Kiem and Austin 2013; Walker and Walker 1987). As a drought-vulnerable group, farmers are expected to require increased future support to build adaptive and proactive drought management strategies (Fennell et al. 2016).

\subsection{Australian Historical National Drought Policy}

In 1992, the National Drought Policy (NDP) was rolled out to manage drought in Australia, addressing a need to shift the perception of drought as a climate abnormality to a "normal component of the operating environment" (Nicholson et al. 2011). A key focus of the policy was to "encourage primary producers and other sections of rural Australia to adopt self-reliant approaches to managing for climate variability" (Department of Agriculture Water and the Environment 2020). In this context, self-reliance means that individual producers hold the primary responsibility for ensuring that their enterprise 
is appropriately and sustainably managed so that periods of financial difficulty can be weathered (Productivity Commission 2009). The policy built upon an Exceptional Circumstances (EC) declaration, listing the conditions under which farmers could not feasibly manage the impacts of drought alone and would thus be provided with financial aid from the states and territories and the Commonwealth (Nicholson et al. 2011).

A national review of the policy was commissioned in 2008, with findings indicating that Australia's NDP was largely not meeting the original objectives, particularly in supporting farmers to improve self-reliance and preparedness for drought (Kiem 2013; Nicholson et al. 2011). A summary of the key findings from this national review is given in Table 1. The findings of this review resulted in EC programmes being phased out over time, which effectively saw an end to the NDP. Since then, National Drought Agreements have been formed but a revised, comprehensive NDP has not been implemented.

EC programmes were a reactive assistance measure that provided aid to producers only after severe impacts had been felt. A future NDP could incorporate more proactive measures and target activities that increase resilience within farming communities (Department of Agriculture Water and the Environment 2020; Kiem 2013; Nicholson et al. 2011). In particular, drought management should seek to plan and mobilise non-drought periods in a way that leaves communities better prepared for drier periods (Kiem 2013).

\subsection{Forecast-based financing}

When managing and responding to natural hazards, the humanitarian sector has observed a shift from crisis management towards predictive and anticipatory approaches

Table 1 Summary of findings from the National Review of Drought Policy in 2008-2009

\begin{tabular}{|c|c|}
\hline Assessment body and purpose & Key findings \\
\hline $\begin{array}{l}\text { Productivity Commission-economic assessment } \\
\text { of drought support measures (Productivity Com- } \\
\text { mission 2009) }\end{array}$ & $\begin{array}{l}\text { EC declarations and drought assistance programmes } \\
\text { did not help farmers improve self-reliance, prepar- } \\
\text { edness, and climate change management } \\
\text { About } 70 \% \text { of farms in drought-affected areas } \\
\text { received no assistance } \\
\text { Assistance programmes inadvertently encouraged } \\
\text { poorly managed farms }\end{array}$ \\
\hline $\begin{array}{l}\text { Expert Social Panel-examination of social impacts } \\
\text { of drought on farm families and rural communi- } \\
\text { ties (Kenny 2008) }\end{array}$ & $\begin{array}{l}\text { EC policy was inequitable and had created feelings of } \\
\text { division and resentment } \\
\text { Rural Australians did not perceive any feelings of } \\
\text { improvement after introduction of assistance pro- } \\
\text { grammes, rather found that they created unneces- } \\
\text { sary stress } \\
\text { Governments should incentivise efforts to prepare for } \\
\text { drought during good periods }\end{array}$ \\
\hline $\begin{array}{l}\text { Bureau of Meteorology (BoM) and Commonwealth } \\
\text { Scientific and Industrial Research Organisation- } \\
\text { future climate patterns (Hennessy et al. 2008) }\end{array}$ & $\begin{array}{l}\text { The one in } 20-25 \text { years EC drought trigger was not } \\
\text { the most appropriate measure in a changing climate } \\
\text { Assessing historical data, rainfall trigger indicated } \\
\text { that many areas of Australia had been drought } \\
\text { declared in more than } 5 \% \text { of years } \\
\text { The frequency and extent of exceptionally hot years } \\
\text { have increased rapidly over past decades and this } \\
\text { trend is expected to continue }\end{array}$ \\
\hline
\end{tabular}


(Coughlan de Perez et al. 2015). Forecast-based Financing (FbF) is one such approach that has been well received by humanitarian agencies (Dinnissen et al. 2020; Wilkinson et al. 2018). This method specifically focuses on providing assistance to community members and households who are most vulnerable to natural hazards, where vulnerability is determined through an assessment of available data ranging from the region's climate vulnerability to socio-economic factors (Dinnissen et al. 2020).

$\mathrm{FbF}$ is a disaster risk reduction system that initiates anticipatory actions during the window of opportunity between early warnings (e.g. based on long-range climate forecasting) and the onset of disaster. When forecast thresholds for a weather or climaterelated hazard are exceeded, the window of opportunity is open, allowing FbF projects to disburse the necessary funds to enable humanitarian actors to implement predetermined early actions to prepare vulnerable communities.

$\mathrm{FbF}$ projects are extremely context-specific, recognising that impacts of a natural disaster will vary depending on the region and the communities involved. Stakeholders decide on region-specific actions to create an Early Action Protocol consisting of three key criteria: triggers, early actions, and financing mechanisms. From this, a standard operating procedure (SOP) is created which outlines detailed information on the early actions to be implemented based on climate triggers. When predetermined climate thresholds (triggers) are exceeded, early actions are initiated to deliver assistance to the most vulnerable communities. Contrary to traditional humanitarian aid efforts, FbF projects require funds to be acquired before a hazard becomes a disaster to enable timely actions that increase preparedness.

While FbF pilot programmes have been undertaken with tropical cyclones, flooding, and cold/heat waves (i.e. rapid-onset hazards), managing risks for a slow-onset hazard, such as drought, through a FbF system is a relatively new and under-researched area. This is predominantly due to the difficulty in identifying the start and end dates, as well as the different phases of a drought and the resulting difficulty in identifying appropriate anticipatory actions for each phase.

However, there is great potential to utilise the slow-onset nature of drought to implement multiple stages of anticipatory actions with varying action lifetimes (Coughlan de Perez et al. 2016; World Food Programme (WFP) 2019). The slow-onset nature of drought allows for a longer lead time between disaster warning and the time of peak damage. Therefore, a more systematic preparedness plan can be created and adhered to during this additional lead time.

In this study, discussing forecast-based action and assistance, we are specifically focused on improving drought resilience by means of $\mathrm{FbF}$ projects which, to the best of our knowledge, to date have been implemented in developing or least developed countries, where there is a greater need for humanitarian aid; no FbF projects have been implemented yet in developed countries with a market economy such as Australia. Furthermore, developing or least developed countries tend to lack historical data of drought events due to the limited availability and capacity of national meteorological services (Rogers and Tsirkunov 2013). To advance the implementation of FbF systems for drought and increase the body of research in this space, a pilot study could be considered in a country that has sufficient historical meteorological data and monitoring capabilities for drought. Given Australia's advanced meteorological service capacity, a FbF drought pilot study could provide a strong foundation for further drought pilots which could be conducted in developing or least developed countries based on the methodology and recommendations of this study. 
An early warning system (EWS) for drought is a tool that has been established to enable actions to increase preparedness (Garcia and Fearnley 2012; Kelman and Glantz 2014). Here, an EWS refers to "the set of capacities needed to generate and disseminate timely and meaningful warning information to enable individuals, communities, and organisations threatened by a hazard to prepare and to act appropriately and in sufficient time to reduce the possibility of harm or loss" (United Nations International Strategy for Disaster Reduction (UNISDR) 2006). In its simplest form, an EWS for drought is the provision of timely climate information, e.g. long-range seasonal climate outlooks, through trusted bodies, that allows groups and individuals exposed to a drought to prepare (World Meteorological Organization (WMO) and Global Water Partnership (GWP) 2016).

In this paper, we present results of our research on investigating whether a Forecastbased Financing assistance approach, which utilises a user-centred Integrated Early Warning System (I-EWS) for drought, has the potential to increase farmers' drought preparedness.

\section{The Australian agricultural sector}

In order to determine whether any assistance approach, in this case $\mathrm{FbF}$, will work for a given country, it is important to understand the role that agriculture and agricultural support play in that nation's economy. Here, we explore key insights into the Australian agricultural sector to assess whether a FbF model would align with the direction that the sector and government policy are taking.

\subsection{Trends in Australian agriculture}

Agricultural exports have seen an increase in Australia throughout the past few decades, with around 70\% exported in the 2018-2019 period (Jackson et al. 2020). The output prices of agricultural commodities are subject to various factors on the global market. This increased dependence on exports means that Australian producers need to continuously refine, improve, and adapt their production and management strategies in order to compete with countries supplying similar products to the global market.

Over the past century, Australia has seen a decrease in the total number of farms and an increase in farm sizes, both in terms of land area and the value of production (Jackson et al. 2020; Productivity Commission 2005). Since the late 1970s, large farms, or those with receipts greater than $\$ 1$ million, have experienced a growth from around 3\% to around 15\% of the farm population (Jackson et al. 2020). The share of total outputs of large farms has also seen a notable increase. Indicative analysis suggests that larger farms in general have higher rates of productivity and profitability, likely due to being able to access positive economies of scale, having better access to innovative technology, and better farm management strategies (Jackson et al. 2020).

Overall, there has also been a significant increase in the productivity growth of the agricultural sector (Gray et al. 2014). Here, productivity growth refers to the adoption of innovative practices and structural adjustment. Technological change and innovation within agriculture, such as the use of satellite technology to assist in decision-making around land use, have driven productivity growth by allowing production of commodities with fewer workers (Jackson et al. 2020). Structural adjustment, that is, the reallocation of resources towards the most productive farmers and sectors, has been found to account for high levels 
of productivity growth in Australian agriculture (Gray et al. 2014; Greenville 2020; Sheng et al. 2015).

\subsection{The drought assistance dilemma}

While it is generally accepted that farmers require some level of drought support, some economists and farmer representatives express concerns about the potential adverse effects of drought assistance (Hughes and Hatfield-Dodds 2018). As discussed in Sect. 2.1, Australian agriculture relies heavily on exports and therefore needs to undergo constant productivity growth to remain competitive. Structural adjustment is critical for productivity growth (Sheng et al. 2015). However, during severe drought periods, increased media attention on the devastating impacts of drought tends to put pressure on governments to provide more visible support for farmers. This introduces what is called the drought assistance dilemma: should there be increased support for farmers who are in distress during severe droughts or should the industry be supported to increase productivity growth? Usually, the government would be the actor expected to make an investment based on a drought forecast. While the government is the only actor discussed here, it should be noted that other support systems for anticipatory action, e.g. peer-to-peer farmer support or forecast-based insurance, do exist. However, discussion on the potential role of other support systems for anticipatory action is beyond the scope of this study.

Since the introduction of the NDP in 1992, it has been acknowledged that Australia has a variable climate and farmers must account for this in their farm business model. Farmers are increasingly being encouraged to be self-reliant and manage their risks to increase their capacity to withstand poor years due to droughts (Productivity Commission 2009), while, at the same time, capitalising on the good years. Farming in Australia is seen as a business and as with any business operation, it comes with a multitude of risks that operators must manage to the best of their abilities.

Since the 1960s, the Australian agricultural sector has observed improvements in productivity growth, indicating that Australian farmers have broadly been successful in managing risks (Greenville 2020). However, this shift to greater self-reliance and risk management is not global, and increasingly Australian farmers are competing on a non-level playing field.

When it comes to the level of support provided to agricultural producers in the world, Australian producers receive some of the lowest levels of subsidies amongst 37 Organisation for Economic Co-operation and Development (OECD) member countries (Greenville 2020). The OECD's measurements indicate that for Australia, around $2 \%$ of producer revenues in the 2016-2018 period can be attributed to government support (Greenville 2020). In stark contrast, in Norway, which has one of the highest levels of agricultural subsidies, around $60 \%$ of producer revenues can be attributed to government support (Greenville 2020).

While producer support in Australia is currently low in comparison with other countries, this was not always the case. Since the 1980s, government support to the agricultural sector has seen a shift from direct producer support to increased general services support. This was largely as a result of policy reforms and deregulations within the agricultural sector (Greenville 2020; Organisation for Economic Co-operation and Development (OECD) 2016). Internationally, direct support measures, such as subsidies, for agricultural sectors have been linked to negative trade impacts (Organisation for Economic Co-operation and Development (OECD) 2016). 
There are concerns that direct producer support disincentivises producers to find better methods to manage their risks (including drought) and increase productivity (Gray et al. 2014). With around 70\% of agricultural outputs being exported (Jackson et al. 2020), and low levels of government subsidies in comparison with other countries (Greenville 2020), Australian farmers need to keep increasing their productivity in order to remain competitive in global markets.

Given the trend for greater self-reliance within the farming sector, consideration must be taken to ensure that any short-term drought assistance does not adversely become a long-term disincentive to self-reliance.

During the EC years, drought assistance was intended to be released to assist farmers only during droughts that would be difficult for the best operators to manage. However, between 2002 and 2008, it was found that about 68\% of farms in EC regions were able to manage without any EC assistance (Productivity Commission 2009). This indicated that most farmers were able to sufficiently prepare for and withstand drought years without assistance. On the other hand, it was found that drought, in addition to impact on agricultural production, does have negative mental health impacts and that those who are most impacted upon are farmers and farm workers (Edwards et al. 2014).

\section{Data and Method}

\subsection{Study region: Northern Murray-Darling Basin}

Using the Northern MDB, Australia's primary agricultural producing region, as a case study, we investigated whether FbF using a user-centred I-EWS for drought has the potential to increase Australian farmers' drought preparedness. We aimed to:

- identify the barriers that drought-vulnerable farmers experience, from the perspectives of financial service providers, that hinder them from increasing their drought preparedness,

- investigate how a user-centred I-EWS for drought might be beneficial for Australian farmers in the Northern MDB, and

- investigate on-the-ground observations of the effectiveness of government assistance measures and barriers to accessing support arrangements.

\subsection{Study design and sampling}

In-depth one-on-one interviews were undertaken with staff of the Rural Financial Counselling Services (RFCS) from Southern Queensland, Northern New South Wales and Central New South Wales to ensure a broad representation of participants from the Northern MDB. This included Rural Financial Counsellors (RFCs), a Business Analyst and a CEO of a services region. The participants were selected based on the following criteria:

- work directly with drought-vulnerable farm operators,

- have a sound understanding of government drought assistance measures, and

- have a sound knowledge of farming and can comment on how drought impacts farming enterprises. 
The purpose of the interviews was to explore the financial impacts of drought upon farming families, investigate the proactivity of government drought assistance, and uncover barriers that farmers experience that hinder them from increasing their drought preparedness. Interviews were semi-structured, approved by the Monash University Human Research and Ethics Committee, with a list of questions prepared beforehand.

A set of semi-structured interview questions was used, consisting of topics around RFCS clients' demographics, drought impacts, drought preparation, drought risk management, and drought assistance measures. As the interviews were conducted orally and the interviewees consulted limited records or statistics when answering the questions mainly relying on their recounted memories of which farmers needed the most assistance or who is more risk averse, these types of recollections could be potentially prone to bias. However, as this study investigated a very recent case of severe drought event in 2019 and recollection of drought impacts was fresh in interviewees' memories, we believe that such potential bias was reduced to minimum.

\subsection{Data collection and analysis}

Interviews were held in June 2020; due to restrictions related to the COVID-19 pandemic, interviews were either over the phone or through a video communication platform. Participants were not provided with incentives or reimbursements.

Audio recordings were made with consent, and interviews were transcribed verbatim. An inductive approach to thematic analysis was undertaken to identify relevant themes and emerging patterns (Braun and Clarke 2006). The qualitative data analysis software, NVivo 12 , was used throughout the analysis of interview data.

\section{Results}

Farmers approach RFCS and become their clients for drought assistance, during times of drought, but historically not prior to drought. The average client of the RFCS was described as being between the ages of 50-70 and running a small-to-medium farming enterprise. However, RFCS staff indicated that they have a wide variety of clients, with a smaller proportion between the ages of 20-40 or above 80 years of age.

Clients also tend to be in the bottom $30-40 \%$ when taking into consideration income levels across all farm businesses. This is generally because the RFCS assist producers who are experiencing financial hardship, rather than farmers who are simply seeking general ongoing financial advice. Depending on the region, farmers had cropping enterprises, livestock, or both. Most clients had a farming background, generally meaning that they have grown up on and/or inherited a family farm. The operations tend to be a family partnership with, in most cases, the male partner predominantly running the hands-on farming operations and the female partner primarily responsible for the bookkeeping and finances of the business. 


\subsection{Drought impacts and response}

Four prominent drought impacts on Northern MDB farmers were identified through the interviews: (i) lower crop yields; (ii) depletion of feed reserves; (iii) depletion of working capital; and (iv) decline in mental health. Detailed description of the impacts that Northern MDB farmers experienced during a severe and prolonged drought is presented in Table 2.

Analysing farmers' response to drought, the following key themes emerged.

\subsubsection{Younger farmers more educated, risk-taking, and adaptable}

Younger farmers were classified as those under the age of 50-55. It was found that younger generation farmers are increasingly becoming more qualified through education and training beyond the premises of the farm. This increase in education level and training has been linked to an increased interest in adopting or trialling new farming methods, technologies, and business strategies. In some cases, where younger farmers are not yet the figureheads for the family enterprise, they will encourage the senior partners to consider adapting new methods.

Younger farmers were also described to be more inclined towards taking on higher debts in order to expand their enterprise, simply because they have more energy and a longer potential working life to be able to repay those debts.

Table 2 Summary of prominent drought impacts on Northern MDB farmers

\begin{tabular}{|c|c|}
\hline Drought impact & Description \\
\hline Lower crop yields & $\begin{array}{l}\text { Crop yields are determined by several factors, including the amount of water } \\
\text { available and soil moisture. It is possible to sow a good crop during a } \\
\text { drought if the rain falls at the right time and if there is adequate soil mois- } \\
\text { ture. Lower income years are expected for croppers during drought times, } \\
\text { however, when a drought extends beyond } 2-3 \text { years, smaller scale cropping } \\
\text { operations begin to suffer from multiple years of reduced or no income }\end{array}$ \\
\hline \multirow[t]{2}{*}{ Depletion of feed reserves } & $\begin{array}{l}\text { Most livestock farmers store at least } 1-2 \text { years supply of feed reserves. When } \\
\text { a drought extends beyond that period and there is no pasture growth, live- } \\
\text { stock farmers will rely on their feed reserves to keep their stock. Once the } \\
\text { reserves have been depleted, stock owners are faced with the decision of } \\
\text { buying fodder at inflated prices or destocking at reduced market prices }\end{array}$ \\
\hline & $\begin{array}{l}\text { In wide-spread and long droughts, farmers often will have to purchase feed } \\
\text { from other states and pay high transport costs }\end{array}$ \\
\hline Depletion of working capital & $\begin{array}{l}\text { A slow deterioration of farmers' financial reserves occurred throughout a } \\
\text { severe and lengthy drought, indicating that because conditions were so } \\
\text { severe, it was extremely difficult to gain a profit, and it many cases, farmers } \\
\text { were experiencing financial losses }\end{array}$ \\
\hline Decline in mental health & $\begin{array}{l}\text { During a severe and lengthy drought, the mental health of farmers can } \\
\text { experience a decline due to the losses incurred. This can impact their abil- } \\
\text { ity to make decisions about their enterprises clearly. In severe cases, some } \\
\text { farmers stop feeding their stock altogether and animal welfare issues were } \\
\text { raised }\end{array}$ \\
\hline
\end{tabular}




\subsubsection{Older farms more risk averse}

Older farmers were generally classified as those above the age of 60-65. It was found that older farmers tended to be more risk averse. They were less inclined to adopt new farming methods and business strategies without the guarantee that they would be effective within their working lifetime. It is likely that this stemmed from the fact that older farmers could not afford to take on risky changes that might result in increased debt levels for them when they are close to retirement.

It was also noted that some older farmers (50-70 years old) coped better mentally in the current drought than younger farmers (30-45 years old) due to their past lived experiences with severe droughts.

\subsubsection{Smaller enterprises are impacted first}

Shortly after onset of a drought, smaller enterprises were reaching out for assistance first. These tended to be husband and wife partnerships. As the length and severity of a drought extends, more enterprises are impacted and their capacity to cope is reduced. The mediumsized operators began approaching RFCS for assistance after around 18 months of drought. In some cases, the largest enterprises sought assistance after three years of drought.

\subsection{Preparing for drought}

Sharing best practices is a good way to strengthen drought preparedness of farming communities. In this study, we investigated how successful farm operators prepare their farm business for drought. Key actions, behaviours, and decisions are outlined as follows:

- Farmers adapt their enterprise operations throughout drought by monitoring property conditions, climate conditions, and market prices. All this information is used to make decisions about expenditure, destocking, when/what to crop, etc.

- To build resilience, operators have expanded their enterprise to access economies of scale and increase their profits during the good periods to be able to withstand longer periods of reduced income.

- Most operators build better farm infrastructure to increase the productivity of their enterprise and manage their risks. This includes additional dams and water tanks, silos, fodder sheds, water infrastructure, and improved fencing.

- Small-to-medium operators will engage in off-farm work to diversify income sources as part of a risk management strategy.

- Most farmers will ensure that they are putting resources (feed, cash, grains) aside during periods of high farming returns to withstand drought periods.

- Debt minimisation was described as an underutilised tool that often smart operators use to manage their long-term risks.

A detailed summary of the best practices and behaviours of successful farm operators in the Northern MDB during drought periods is presented in Table 3.

Lower business management skills in less successful farm operators were identified as the key issue for insufficient preparedness for drought. The major barriers for drought preparedness that keep farm operators from being able to improve their enterprises included: 
Table 3 Key actions that the best farm operators in the Northern MDB take to increase their drought preparedness

Action Description

Adapting enterprise operations throughout drought The best farm operators monitor climate conditions and market prices throughout a dry period, to make decisions about their operations

Monitoring budgets: operators monitor expenditure and income to decide whether a change in purchases is necessary. For instance, if income is reduced, expenses will be reduced appropriately

Livestock owners: during a longer drought period, most farmers run out of fodder reserves. They are then faced with the decision to either destock, against their stock onto other properties, or keep stock and purchase fodder at high prices. The best operators will be monitoring their feed reserves, stock prices, and climate forecasts to determine when they need to do a partial or full destock

Cropping: operators are monitoring past and current climate conditions, as well as looking at forecasts, to determine which crops to sow, how much to sow, and whether or sow at all in some cases

Expanding enterprise size

Operators expand their enterprises by purchasing more properties. This allows for greater profits during good periods, through economies of scale, which can extend an enterprise's ability to withstand longer periods of reduced income. In some cases, operators will purchase properties in different regions to diversify the climate conditions that they have access to. For instance, if one property experiences reduced rainfall, the operator can take their livestock to another property with better pasture and rainfall

Building better infrastructure and keeping them at Most farm operators are building farm infrastructure to increase the productivity of their enterprise and manage their risks. Operators will build the following:

- Dams and water tanks to store water.

- Silos to store grain.

- Fodder sheds for feed reserves.

- Water infrastructure (pipes, bores) to enable water access throughout the property.

- Fencing to keep wild animals out

The best operators will clean their infrastructure to ensure that they are at maximum capacity when needed. For instance, dams will be desilted before it rains so that water can enter the dams easily

Diversifying income sources

For small-medium operations, oftentimes off-farm work will be involved in some capacity, as part of a risk management strategy. Either the farmer's partner will have an off-farm job, some contracting work for other farms might be involved, or in some cases, some farmers will shut down their farming operation during severe drought periods and work off-farm. Off-farm work can relieve the financial pressure from the farming enterprise during periods of drought and provide a steady income 
Table 3 (continued)

\begin{tabular}{ll}
\hline Action & Description \\
\hline Putting resources aside (feed, cash, grain) & Most farmers will ensure that they have reserves of \\
& some sort that they build up during good periods. \\
& This includes feed for livestock, grain, hay, and \\
& financial reserves \\
& Where an enterprise is larger, operators can manage \\
& their income so that they have sufficient funds put \\
& aside to weather the lower income years \\
& Larger operations with greater holding capacity can \\
& store extra grain, hay, or fodder that they make on \\
& farm. During drought periods, they are then able to \\
& sell this off to other farmers as an extra source of \\
& income \\
& Operators with longer term vision tend to be more \\
& aware of their debt levels and seek to minimise their \\
& debts where possible to decrease financial risks in \\
the long term. Individual farming enterprises differ & so the decision to acquire extra debt for cash flow is \\
complex and requires a realistic assessment of cur- & rent financial capacity. During higher income years, \\
smarter operators will be looking to minimise their & debt rather than absorbing the extra profits back into \\
their cash flow
\end{tabular}

(i) lack of business skills; (ii) lack of financial agility and adaptability; (iii) inability to make timely decisions in drought; (iv) inability to take appropriate measures during profitable periods; (v) reliance on government assistance; and (vi) complexities of drought. A detailed summary of key barriers that hinder farm operators in the Northern MDB in increasing their drought preparedness is presented in Table 4.

\subsection{Forecasting tools and risk management}

Weather (short-term) and climate (long-range) forecasts are essential information for decision-making in drought preparedness. This section outlines key information from responses to questions around the use of forecasting information and actions that would be taken in response to a drought early warning.

\subsubsection{Forecasting tools and resources}

All RFCS clients used forecasting tools to some extent. Most clients accessed free forecasting information and a small percentage have paid forecast subscriptions. The types of resources included the weather forecast on television; weather applications on mobile phones (Elders, yr.no); websites (Elders.com, bom.gov.au); The Land newspaper.

There was a general agreement that most clients looked at the forecasts, particularly the long-range forecasts, without altering their farm operations as a result. That is, long-range forecasts generally are not consciously used to make decisions around production on the farm. But it was also found that some farmers became more apprehensive about making big or critical decisions on their farms when long-range forecasts indicated unfavourable 
Table 4 Key barriers that hinder farm operators in increasing their drought preparedness

Barrier Description

Lack of business skills

Lack of adaptability

Poor operators are described as lacking the business knowledge needed to maximise the capabilities of their operations. A lack of business skills will mean reduced understanding of the operation's financial performance and a lack of a business plan for making decisions about the operation

Interviewees described a distinction between lifestyle farmers and business farmers. Lifestyle farmers were described as having insufficient knowledge to manage the business side of their operation, which often led them to suffer during drought periods

A lack of business skills was often described within the older demographic, above 60. It was also often associated with lower education levels in the older demographic of farmers

Interviewees described a lack of desire to adapt farming practices as a major barrier in farmers. This lack of adaptability means using the same farming practices as their parents and grandparents, being resistant to adopt new technologies, and not being sensitive to climate conditions

Lack of time: This was described as a trait more common in older farmers, who are often risk averse and hesitant about making mistakes due to a lack of time to rectify big losses

Low education levels: Lack of willingness to adapt was also associated with reduced education levels, again often in the older demographic

Inability to make timely decisions in drought The duration of a drought is often uncertain, leaving farmers to deliberate some difficult decisions

Holding on to stock: A common decision for livestock owners during a drought is whether to do a partial or full destock. Interviewees indicated that farmers who kept their stock for too long faced significant losses as a result of having to pay for fodder at inflated drought-fuelled prices

Farmers often hold onto their stock for too long because they are breeding stock that have been chosen for their genetics. Often farmers will have invested a significant amount of money, over many years, to breed a herd they feel performs best for their conditions. It can be very difficult-even highly emotional - to part with a herd with many years of breeding behind it

Lack of a plan/triggers: Another reason for acting too late was the lack of clear trigger points, or a plan, for when to make critical decisions, such as destocking, during a drought 
Table 4 (continued)

Barrier Description

Inability to take appropriate measures during profitable periods

Reliance on government assistance

Complexities of drought
Droughts are a part of the Australian farming landscape, and hence farmers should be preparing for them. Some interviewees suggested that the best time to be planning for a drought is when you are not in a drought. However, some farmers either are unable to prepare effectively or lack the knowledge needed to prepare beyond the simple methods

Stigma against seeking help: During non-drought periods, in some small towns, there is a stigma against seeking assistance which can stop some farmers from reaching out to organisations such as the RFCS to ask for guidance, education, or training

Farm is not viable: Some operators are not be able to prepare for a drought because their farming enterprise is simply not viable in the long term. These farmers do not generate enough profits during higher income years to be able to put funds aside for low-income years

High debt levels: In some cases, putting funds aside during higher income years is not possible because farmers need to pay back the interest on their loans

In some cases, there are farmers who are not managing their business effectively and rely on government assistance to keep their enterprise running. Interviewees indicate that these farmers are hindered by government assistance because it keeps them continuing with an unviable farming business. Often these farmers will be employing poor management strategies, such as overstocking, and the provision of government assistance stops them from reassessing their strategies

Droughts are a complex natural hazard and sometimes, smart and prepared operators are also caught out

Green drought': A green drought occurs when there is shallow soil moisture and pastures looks green, but a closer look reveals that there is not much grass and it is very short

Constant natural disasters: In cases where droughts, floods, or fires are occurring immediately after each other, the rate of recovery for farmers is severely reduced due to the amplified impacts created by the events

Some droughts are just too long: There is a point where a drought exceeds the reasonable duration for even the best operators to manage the impacts

conditions ahead. In other words, while they would not have discrete trigger points at which they would use a long-range forecast to knowingly change a decision, they would become more cautious overall with every decision if there was talk of drought, indicating that subconsciously the long-range forecasts were a factor.

It is essential to understand how far in advance of a drought event farmers need to receive early warnings to be able to take reasonable drought preparedness actions. Results indicated that a three to six-month long-range climate outlooks and associated warnings 
were sufficient to allow cropping and livestock operators to have enough time to prepare their operations for a dry period.

\subsubsection{Actions that farming enterprises would take to reduce losses}

We also investigated if an advance warning of a drought was available and credible, what would be actions that farming households could take to reduce losses. The key responses included: (i) deciding whether/when to destock; (ii) planning timing and type of crop; (iii) monitoring feed reserves; and (iv) prepare water infrastructure. A detailed summary of the key drought preparedness actions that could be undertaken provided an early warning was announced is presented in Table 5 .

\subsubsection{Apprehension around the use of long-range climate forecasts}

Results suggest that single failures in the past had made some farmers reluctant to put their faith fully into seasonal climate forecasting. Severe drought periods can be a highly emotional time for farmers, and false alarms in long-range climate forecasting have the potential to significantly impact people's emotional well-being. In the case that a user-centred I-EWS for drought is piloted in Australia, care should be taken to provide education about how such a probabilistic outlook system differs from a more deterministic short-range weather forecast.

Table 5 Summary of key drought preparedness actions that could be undertaken provided an early warning was announced

\begin{tabular}{lc}
\hline Action & Description \\
\hline Deciding whether/when to destock & $\begin{array}{c}\text { Some farmers did not have a decision-making frame- } \\
\text { work for when a partial or full destocking would need } \\
\text { to occur during a drought. With an advance warning, } \\
\text { farmers could assess their capacity to hold stock and } \\
\text { consider the expected forecast to determine whether a } \\
\text { partial/ full destocking would need to occur } \\
\text { This will involve assessing stock prices, feed reserves, } \\
\text { and fodder prices alongside the early warning infor- } \\
\text { mation to determine the action that would result is } \\
\text { the least amount of loss for the enterprise } \\
\text { For croppers, the type of crop they sow and when they } \\
\text { sow during a drought is important in determining the } \\
\text { yields that they will get. Combining early warning } \\
\text { information with information about factors such as } \\
\text { soil moisture can help croppers decide whether they } \\
\text { need to sow a crop that is more drought-resistance } \\
\text { and when it is best to sow it } \\
\text { Monitoring feed reserves to ensure that there is enough } \\
\text { to feed livestock for the upcoming dry period. If fod- } \\
\text { der prices are low, and there is a high likelihood of } \\
\text { an upcoming dry period, operators may decide to buy } \\
\text { fodder if needed } \\
\text { Desilting dams and water tanks so that they can catch } \\
\text { maximum rainfall when it does rain }\end{array}$ \\
Monitoring feed reserves & \\
\hline &
\end{tabular}


However, results indicate that overall, early warning information has potential to provide an extra source of needed information to assist farmers with critical decision-making, alongside other tools and information sources.

\subsection{Government drought assistance measures}

This section summarises interview responses around assistance measures that have been perceived as increasing drought preparedness, major difficulties in accessing assistance, and drought assistance politics.

\subsubsection{Concessional Loans: for infrastructure and refinancing debt}

Results demonstrated that the most adopted form of government drought assistance tended to be low interest concessional loans provided by state governments. The loans allow enterprises to build infrastructure such as storage sheds for hay and feed, water infrastructure, grain silos and feeding equipment. In NSW, The Rural Assistance Authority has the Drought Assistance Fund (DAF) and the Farm Innovation Fund (FIF), both which provide concessional loans for farmers. The federal government provides loans of various sizes through the Regional Investment Corporation (RIC).

These concessional loans were increasing drought preparedness by encouraging farm operators to upgrade infrastructure that they otherwise would not have done.

These loans are also available on a continuous basis, drought, or non-drought period. However, results indicated that these loans more often tended to be taken up during drought periods. Interviews revealed farmers' perception that for smaller farm operators with reduced cash flow, it may not be in their best interest to take on more debt during drought.

Concessional loans were also used to refinance debts in some cases. While not explicitly related to drought preparedness, refinancing debts is a form of debt minimisation that benefitted farmers greatly.

\subsubsection{Farm management deposits (FMD)}

Farm Management Deposits (FMDs) encourage (via tax incentives) farmers to set aside money during profitable years, for use during years when they experience losses. FMDs were described as an underutilised tool by interviewees. This was largely explained by the scale of the enterprises of clients that RFCS see. FMDs are viable when an enterprise generates enough profit during good farming conditions to be able to put some of it aside and into a FMD. The number of clients who were able to use FMD were generally described as being low for interviewees.

\subsubsection{Time delay in processing applications}

Results indicated that one of the biggest complications with drought assistance applications was often the time applicants had to wait in order to receive the assistance itself. This was often mentioned in discussions about the RIC's loan but also some state government loans such as the DAF. With the RIC loans, on average, applicants would have to wait six months after they had submitted their application to receive a response. Some clients had been waiting over a year. 
The impact of the time delay on farmers is that they are usually unable to undertake their desired project until they receive the funds. Due to the uncertainties around a drought, several things can go wrong in this wait time.

\subsubsection{Increased applications during drought periods}

Time delays in receiving funds from government departments were often indicated to be a result of the high volumes of applications that processing departments, such as the RIC, were receiving during times of drought. Loan applications often involve sensitive financial information and hence security processes, meaning staff must have the security clearances to be able to process them. When there is a sudden increase in applications during drought periods, it can be difficult to source appropriately trained and accredited staff, knowing as well that once the drought period has passed, they would likely not be needed. Finding temporary qualified employees to process drought assistance applications proves to be a difficult process in itself. A user-centred I-EWS for drought may be useful in recruiting and upskilling staff needed during drought.

It was also found that during times of drought, there are not enough services or people on the ground who will help farmers through the application process without a cost. Operators who usually seek paid assistance will attempt to save money where possible and during drought periods, that means they will seek assistance with the RFCS. This in turn results in high influxes of clients for the RFCS during drought.

\subsubsection{Drought assistance is reactive}

The timing of the assistance has been identified by interviewees as a problem; assistance coming late or clients seeking assistance too late.

Results indicated that assistance for drought is to large extent reactive and often arrives late. These comments were generally made about transport rebates and assistance measures that were announced after several months of drought had been declared in many areas.

This reactiveness in releasing drought assistance measures was described as increasing frustration in clients. Without knowing the types of assistance that will become available during a drought, farmers are unable to plan for it.

Participants noted that their clients also tend to seek assistance too late, when drought impacts have meant that they are no longer able to continue without assistance.

Uncertainties around a drought, and the time delay for farmers take a proactive approach, are often related to farmers' trust in accuracy of drought forecasts. Seasonal and multi-week climate forecasts are important inputs into user-centred I-EWS for drought (Kuleshov et al. 2019, 2020; Bhardwaj et al. 2021). In Australia, the Bureau of Meteorology uses dynamical climate model ACCESS-S (Australian Community Climate and Earth-System Simulator - Seasonal) as its current operational seasonal prediction system. In general, ACCESS-S has a high skill for forecasting Australian rainfall on seasonal and multi-week scales. However, a reduction in skill with rainfall forecast lead time (e.g. going from fortnight one to fortnight three) is typical of long-range forecasts (Hudson 2017). Similarly, interview discussions revealed farmers' perception that seasonal outlooks (three months ahead) in the region are less skilful than monthly outlooks (Bhardwaj et al. 2021; Aitkenhead et al. 2021). 
If the time delay was reduced so that the payout happened based on the forecast, and level of trust in drought prediction would be higher, then assistance would be timely to help clients to continue operating.

\section{Discussion}

This study investigated whether a FbF assistance model, which utilises a user-centred I-EWS for drought, would be a suitable approach for increasing the drought preparedness of Australian farmers. The results of the interviews are useful and interesting, providing farmers' perspective and recommendations on proactively preparing for drought based on their expert knowledge and best practices.

\subsection{The need to build Australian farmers' resilience}

Self-reliance in farm operators has been actively encouraged since 1992, when Australian drought policy began to view drought as a normal component of the operating landscape for agribusiness (Department of Agriculture Water and the Environment 2020). To that end, there is an expectation that farm operators will take reasonable actions and planning to ensure that their operations can manage the impacts of drought years (Productivity Commission 2009).

$\mathrm{FbF}$ is structured to ensure that each region-specific pilot has established SOPs prior to drought events. These SOPs outline the early actions that will be implemented to enable vulnerable households to prepare appropriately. The results indicate that some operators become more vulnerable to the impacts of drought because they are failing to prepare sufficiently during higher income years and neglect to plan for drought. In this case, FbF assistance possesses similar risks as EC assistance measures, as it may in fact discourage selfreliance and hence shelter unviable farm operators with poor management strategies from the need to reassess their methods (Productivity Commission 2009).

In Australia, farm operators are primarily responsible for their enterprises' drought preparedness, thus they should already be creating drought SOPs themselves, detailing action plans for different climate and market conditions. Results suggest that lower tier farmers are not equipped with the knowledge to create such detailed plans during non-drought periods. In some cases, such plans are not prioritised by farmers. This suggests a need to encourage farmers to create drought SOPs in non-drought periods.

While FbF provides some advances from previous EC arrangements; both in terms of the measures used to assess assistance (Coughlan de Perez et al. 2015, 2016; Wilkinson et al. 2018), and the implementation of detailed SOPs and greater proactivity (Dinnissen et al. 2020), in a market economy such as Australia a FbF model may act contrary to the encouragement for greater self-reliance and resilience in farming communities (Gray et al. 2014; Greenville 2020). This is because FbF assistance is delivered to certain households and communities that are assessed as being vulnerable. Targeted drought assistance runs the risk of being divisive, particularly during severe drought periods where the emotional toll of drought can cause farmers to become more vocal about the differences in assistance levels (Edwards et al. 2008). This then has the potential negative impact of decreasing productivity growth within the agricultural sector (Gray et al. 2014). 


\subsection{The need for increased business knowledge}

In order to assess whether FbF may increase drought preparedness in Australian farmers, it is imperative to understand the barriers that hinder farmers in taking the appropriate preparatory actions to manage drought impacts.

The results of this study outlined the following factors as barriers to drought preparedness: (i) lack of basic business skills; (ii) lack of financial agility and adaptability; (iii) inability to make timely decisions in drought; and (iv) inability to take appropriate preparatory measures during profitable periods. Considering an appropriate approach to assistance in the identified areas of farmer weakness, it is recommended to provide targeted $\mathrm{FbF}$ assistance, e.g. extension services could support farmers with business skills and drought preparation based on the forecasted event.

A commonality between these identified barriers is a lack of sound business management skills, that is, having a clear knowledge of how to create plans and make business decisions based on cash flows, market prices, and climate conditions. While farmers have in-depth knowledge about crops and livestock, without a sound understanding of how to make their business profitable and more importantly, viable in the long term, they are limited to making decisions that only benefit the short term. This is somewhat expected given that farmers who are clients of the RFCS generally experience financial hardship, causing them to seek financial counselling. However, it highlights that dedicating increased efforts towards increasing business management literacy—potentially through using RFCS during good times-may be one key to increasing drought preparedness efforts.

Organisations such as the RFCS play a key role in assisting farmers by increasing their capacity to make decisions that are in their best business interest. Results of this study indicate that during times of drought, the RFCS are themselves forced to be reactive as influxes of farmers ask for assistance with drought application forms; suggesting that the critical assistance that RFCS can provide tends to be reduced at the very time they are needed most. A user-centred I-EWS for drought would be as beneficial to the RFCS, as it would be for the farmers themselves, in allowing the RFCS to plan staff numbers and internal training ahead of drought periods, thus ensuring the best financial advice and training to farmers are maintained during critical times of drought. RFCS staff may also be trusted community members who can aid in increasing response capacity for their local communities once a warning is issued.

\subsection{Drought preparedness during non-drought years}

During severe drought periods, the RFCS receive an influx of farmers when they are no longer able to continue managing their enterprises without assistance. Results of this study suggest that operators would benefit greatly from seeking assistance long before the situation becomes critical. Reactive drought management can result in snap decisions made during times of heightened stress, and hence may not always be in the best interest of those impacted.

Addressing drought preparedness during non-drought periods has the potential to increase the resilience of farmers and decrease the incurred losses during drought periods. The RFCS are in a position where they have been able to accumulate farmers' information throughout the years. It is recommended that they contact farmers during the recovery phase after a drought period to reassess their farm's viability, when farmers 
still recall the impacts of the drought and recognise the need to prepare or change their practices prior to the next drought. While some period should be allowed to let cash flow increase, there is a window of opportunity during the drought recovery phase that should be capitalised on by encouraging a post-event financial and operations review.

Assessing a farm's long-term viability is a critical step in assisting farmers to make more informed decisions about their enterprise. Generally, if farmers are unable to generate enough profits during good farming periods to be able to put aside funds for lowincome years, then their farms are not viable, and they need to be looking at ways to change their current practices and/or diversify their income.

\subsection{Providing farmers with decision-making tools}

While non-drought periods are crucial for increasing drought preparedness, the business decisions made during a drought period can significantly impact an enterprise's ability to withstand the drought. While in drought, operators face difficult decisions around managing their crops, stock, cash flow, and farms. A major business priority is to minimise losses during a drought, rather than increasing profits. With the uncertain nature of drought and the various other factors at play (Ding et al. 2010; Fennell et al. 2016; Mishra and Singh 2010), the task of making decisions during drought periods becomes complex.

A user-centred I-EWS for drought has the potential to provide farmers with cautionary tools to consult when making decisions. Results suggest that farmers who suffered significantly in the current drought were unable to make timely decisions. Results of a study on a user-centred I-EWS for drought in the Northern MDB indicated that farmers would be 'subconsciously cautious' if provided with an early warning of drought, which in turn would make them more watchful and vigilant with business-related decisionmaking (Bhardwaj et al. 2021). Severe drought impacts can cause significant emotional distress for farming families (Fennell et al. 2016; Walker and Walker 1987), reducing their ability to make rational decisions for their business. Providing early warning information to farming communities may help reduce some of this emotive decision-making as it means they can make decisions and set triggers for action when they are in less severe conditions and consequently under less stress.

A user-centred I-EWS for drought that incorporates agricultural climatic inputs and thorough community consultation to guide its delivery is in line with the Australian government's direction towards supporting the agricultural sector as a whole rather than individual producers (Greenville 2020). This would be crucial in providing communities with appropriate decision-making tools in times of need (Andersson et al. 2020). In this way, such a system could then become part of a farming operation's SOP, containing trigger points for critical drought decisions, that is devised well ahead of a drought event, when emotional strain and uncertainty are minimised.

\subsection{Proactivity versus reactivity}

A reactive drought management system has significant repercussions on the ground. Results indicated that when a new assistance measure is announced during a drought, there tends to be an influx of client numbers and applications for the assistance. The RFCS 
responsible for processing applications may find themselves under-prepared for the new measures. As a result, application processing times extend beyond several months, while farmers are left waiting for funds to become available, and significant on farm impacts may occur during that lengthy wait period.

Results suggest that farmers, financial service providers, and RFCS at times have to address unforeseen issues that have surfaced as a result of a reactive system. For instance, RFCS may have to assist numerous new clients with submitting application forms for drought assistance, rather than being available to work in depth with those whom are experiencing potentially avoidable financial hardship. During droughts, it is critical to ensure that key staff from the RFCS can undertake meaningful work with clients beyond helping them fill out forms for government assistance.

In developing proactive action plans to assist stakeholders in responding to drought, $\mathrm{FbF}$ demonstrates a clear strength. Predetermined SOPs outline clearly when assistance measures are to be implemented, in response to predetermined climate triggers, and what the responsibilities of stakeholders are throughout the process. Further, a user-centred I-EWS for drought can provide the climate triggers to help governments themselves make plans and communicate how they will respond if the drought worsens. Such a use of a usercentred I-EWS for drought, by decision- and policy-makers to fine tune an existing drought plan based on the nature of an emerging drought event, may be a critical component of future drought policy (Wilhite et al. 2014).

Overall, the results of this study suggest that Australian farmers can be supported best by providing a clear, proactive drought plan co-ordinated between all levels of government. While there is an expectation that operators will be self-reliant, there is a limit to this which relies on effective drought response systems to be set on a national and state level. $\mathrm{FbF}$ in its current form will likely not be effective in supporting the Australian agricultural sector and encouraging self-reliance on an individual level. However, a user-centred I-EWS for drought has potential to provide a basis for farmers, service providers, and governments to make decisions that are implemented and communicated well ahead of the most critical times.

\section{Conclusions}

This research demonstrated that greater proactivity and early actions are critical for the best management of drought. Historically, encouraging drought preparedness has been a critical task for countries with significant agricultural production, particularly as climate change increases the severity, frequency, and duration of drought events in many of the key agricultural regions of the world. In Australia, farms are treated as business operations, with the responsibility for drought preparedness resting predominantly on individual farming operations. Hence, drought assistance needs to be delivered in such a way that it does not discourage self-reliance. In this study, effectiveness of FbF assistance to farmers provided by the government was investigated. There are other forms of forecast-based assistance and the pathways by which that assistance would reach farmers; they can be investigated in further research.

This study suggests that a contemporary FbF approach is more suitable in developing countries where farmers, including subsistence farmers, may not have the financial or technical ability to create both long-term and medium-term plans to proactively change course prior to, and while within, a period of drought. FbF typically focuses on providing direct 
assistance to vulnerable individuals or communities and places significant emphasis on the role that supporting bodies play, and the trigger points for their involvement or injection of funds.

Providing direct producer support to drought-vulnerable operators may work against the significant productivity growth that has been observed in the Australian agricultural sector, as a result of structural readjustment. However, encouraging farming operations, and likewise government agencies such as the RFCS and even government drought policy, to proactively plan for drought as a foreseeable climate risk will have greatest financial benefit for Australian farmers and agribusinesses.

A major barrier for lower performing farmers in increasing drought preparedness was identified as being a lack of business management skills. It was also found that lower performing farmers have a reduced capacity to make critical business decisions during severe droughts, as a result of emotional distress and the uncertainty a drought brings. They also tended to react too late, resulting in ineffective decisions being made and significant business losses incurred.

A need for a post-drought event review of a farm's financial health and options, possibly in consultation with RFCs, has been clearly identified. This study found that farmers tend not to seek drought assistance during good farming periods, when they are best positioned both mentally and financially to create drought management plans. During the drought recovery phase, farmers recall the impacts of the drought and the decisions they did or did not take and are likely to recognise the need to prepare or change their practices prior to the next drought.

In a FbF system, supporting bodies create SOPs that are devised in advance of a drought, however in Australia, farmers should be encouraged to create their own SOPs that outline their enterprises' responses to climate and market triggers. A user-centred I-EWS for drought can provide detailed trigger points for farmers to employ in their drought management plans. A user-centred I-EWS for drought can also assist the RFCS, and similar organisations, in preparing their workforce for events that may lie ahead, and hence enable staff to work most effectively to deliver the needed financial assistance prior to severe drought. Likewise, a user-centred I-EWS for drought may be an effective means for all tiers of government to trigger policy reviews or implement support levers.

Climate change projections indicate that changes in precipitation over the twenty-first century will not be uniform, and in many mid-latitude and subtropical dry regions, mean precipitation will likely decrease under the RCP8.5 scenario (IPCC 2014). This implies that "Rural areas are expected to experience major impacts on water availability and supply, food security, infrastructure, and agricultural incomes, including shifts in the production areas of food and non-food crops around the world (high confidence)" (IPCC 2014). This will have an adverse impact on developing and least developed countries, and on small island developing states in Africa, Asia, South America, the Pacific, etc., which have large proportion of rural population and heavily rely on productivity of agriculture. As such, reliable sub-seasonal to seasonal drought forecasts are becoming even more essential to inform decision-making in climate change adaptation and disaster risk preparedness. However, in developing and least developed countries, and in small island developing states, access to accurate drought forecasts on various time scales (weeks, months, seasons, and longer) is rather limited. It is a priority to strengthen capacity of national meteorological services and disaster management offices in vulnerable countries to obtain and interpret drought forecasts. This will significantly contribute to developing an effective user-centred integrated EWS for drought (Bhardwaj et al. 2021) for vulnerable countries and provide 
reliable drought early warnings which will trigger appropriate SOPs as part of national or regional $\mathrm{FbF}$ projects.

Findings have highlighted that clear proactive decision-making is central to drought management, be it in developed, developing or least developed countries. Policy-makers, government agencies, and support services would find a proactive approach supported by a user-centred Drought Early Warning System equally critical in creating their own drought plans.

Acknowledgements Interviewed staff of the Rural Financial Counselling Services from Southern Queensland, Northern New South Wales, and Central New South Wales provided input to analysis on improving drought resilience in Northern Murray-Darling Basin farming communities. John Sims provided insights into the Australian drought policy space, as well as valuable comments on improving the initial version of the manuscript.

\section{Declaration}

Conflict of Interest The authors declare that they have no conflict of interest.

\section{References}

Andersson L, Wilk J, Graham LP, Wikner J, Mokwatlo S, Petja B (2020) Local early warning systems for drought - could they add value to nationally disseminated seasonal climate forecasts? Weather Climat Extrem. https://doi.org/10.1016/j.wace.2019.100241

Australian Bureau of Statistics, Australian Bureau of Agricultural and Resource Economics and Sciences, bureau of rural sciences (2009) socio-economic context for the Murray-Darling Basin

Aitkenhead I, Kuleshov Y, Watkins A, Bhardwaj J, Asghari A (2021) Assessing agricultural drought management strategies in the northern murray-darling basin. natural hazards. https://link.springer.com/artic le/10.1007/s11069-021-04884-6

Bhardwaj J, Kuleshov Y, Watkins A, Aitkenhead I, Asghari A (2021) Building Capacity for an integrated user-centred early warning System (I-EWS) for drought in the Northern Murray Darling Basin. Nat Hazards 107(1):1-26. https://doi.org/10.1007/s11069-021-04575-2

Braun V, Clarke V (2006) Using thematic analysis in psychology. Qual Res Psychol 3:77-101

Bureau of Meteorology, CSIRO (2018) State of the climate 2018. http://www.bom.gov.au/state-of-the-clima te/. Accessed 18/08/2020

Coughlan de Perez E et al (2016) Action-based flood forecasting for triggering humanitarian action hydrology and earth system. Sci Discuss. https://doi.org/10.5194/hess-2016-163

Coughlan de Perez E, Hurk Van Den B, Aalst Van MK, Jongman B, Klose T, Suarez P (2015) Forecastbased financing: An approach for catalyzing humanitarian action based on extreme weather and climate forecasts. Nat Haz Earth Syst Sci 15:895-904

Crimp SJ et al (2010) Managing Murray-Darling Basin livestock systems in a variable and changing climate: challenges and opportunities the. Rangel J 32:293-304. https://doi.org/10.1071/RJ10039

Department of Agriculture Water and the Environment (2020) History of Drought Policy and Programs. Accessed 30th March 2020

Ding Y, Hayes MJ, Widhalm M (2010) Measuring economic impacts of drought: A review and discussion Disaster Prevention and Management. 20 434-446. https://doi.org/10.1108/096535611111617 52

Dinnissen S, Faucet J, Van TN, Van TV, Dinh TT, Quang TN (2020) Fostering anticipatory humanitarian actions for heatwaves in hanoi throughforecast-basedfinancing. Climate Servic. https://doi.org/ 10.1016/j.cliser.2020.100171

Edwards B, Gray M, Hunter B (2008) Social and economic impacts of drought on farm families and rural communities: submission to the Productivity Commission's inquiry into government drought support. Aust Inst Fam Stud

Edwards B, Gray M, Hunter B (2009) A sunburnt country: the economic and financial impact of drought on rural and regional families in australia in an era of climate change Australian. J Lab Econ 12(109):131

Edwards B, Gray M, Hunter B (2014) The impact of drought on mental health in rural and regional Australia. Soc Indic Res. https://doi.org/10.1007/s11205-014-0638-2 
Fennell KM, Jarretta CE, Kettlera LJ, Dollman J, Turnbull DA (2016) "Watching the bank balance build up then blow away and the rain clouds do the same": A thematic analysis of South Australian farmers' sources of stress during drought. J Rur Stud 46:102-110

Garcia C, Fearnley CJ (2012) Evaluating critical links in early warning systems for natural hazards. Environ Hazards 11:123-137. https://doi.org/10.1080/17477891.2011.609877

Gray EM, Oss-Emer M, Sheng Y (2014) Australian agricultural productivity growth: past reforms and future opportunities. ABARES, Canberra

Greenville J (2020) Analysis of government support for Australian agricultural producers. ABARES, Canberra. https://doi.org/10.25814/5ec71d9ccf774

Hennessy K et al. (2008) An assessment of the impact of climate change on the nature and frequency of exceptional climatic events

Hudson D et al (2017) ACCESS-S1 The new Bureau of Meteorology multi-week to seasonal prediction system. J South Hemisph Earth Syst Sci. https://doi.org/10.22499/3.6703.001

Hughes N, Hatfield-Dodds S (2018) Helping farmers in distress doesn't help them be the best: the drought relief dilemma. https://theconversation.com/helping-farmers-in-distress-doesnt-help-thembe-the-best-the-drought-relief-dilemma-105281. Accessed 20/06/2020

IPCC. (2014). Climate Change 2014: Synthesis Report. Contribution of Working Groups I, II and III to the Fifth Assessment Report of the Intergovernmental Panel on Climate Change Core Writing Team, R K. Pachauri and L A. Meyer (eds). IPCC, Geneva. 151

Jackson T, Zammit K, Hatfield-Dodds S (2020) Snapshot of australian agriculture 2020. Australian Bureau of Agricultural and Resource Economics and Sciences, Canberra

Kelman I, Glantz MH (2014) Early Warning Systems Defined

Kenny P (2008) It's about people: changing perspectives on dryness: a report to government. Drought Policy Review Expert Social Panel Department of Agriculture, Fisheries and Forestry, Canberra

Kiem AS (2013) Drought and water policy in Australia: Challenges for the future illustrated by the issues associated with water trading and climate change adaptation in the Murray-Darling Basin. Glob Environ Chang 23:1615-1612

Kiem AS, Austin EK (2013) Drought and the future of rural communities: opportunities and challenges for climate change adaptation in regional Victoria. Aust Glob Environm Change 23:1307-1316

Kuleshov Y, Kurino T, Kubota T, Tashima T, Xie P (2019) WMO Space-Based Weather and Climate Extremes Monitoring Demonstration Project: First Outcomes of Regional Cooperation on Drought and Heavy Precipitation Monitoring for Australia and Southeast Asia. In. https://doi.org/10.5772/ intechopen. 85824

Kuleshov Y et al. (2020) Climate Risk and Early Warning Systems (CREWS) for Papua New Guinea. In. doi: https://doi.org/10.5772/intechopen. 85962

Lloyd-Hughes B (2013) The impracticality of a universal drought definition. Theoretical and Applied Climatology. 117. (1-3). 607-611. https://doi.org/10.1007/s00704-013-1025-7

Mishra AK, Singh VP (2010) A Rev Drought Conc J Hyd 391:202-216. https://doi.org/10.1016/j.jhydr ol.2010.07.012

Murray-Darling Basin authority (2019) Murray-Darling Basin Authority annual report 2018-19

Nicholson M, Bruce S, Walcott J, Gray J (2011) Elements of a national drought policy: the Australian context. World Meteorological Organization, Washington DC

Organisation for Economic Co-operation and Development (OECD) (2016) Evolving agricultural policies and markets: implications for multilateral trade reform. OECD Publishing, Paris

Productivity Commission (2005) Trends in Australian Agriculture. Canberra

Productivity Commission (2009) Government Drought Support-Productivity Commission Inquiry Report. Melbourne

Rogers DP, Tsirkunov VV (2013) Weather and climate resilience: effective preparedness through national meteorological and hydrological services. World Bank, Washington DC

Sheng Y, Jackson T, Gooday P (2015) Resource reallocation and its contribution to productivity growth in A ustralian broadacre agriculture. Aust J Agric Resour Econ 61:56-75. https://doi.org/10.1111/14678489.12137

United Nations International Strategy for Disaster Reduction (UNISDR) (2006) Global Survey of Early Warning Systems. Bonn, Germany

Walker LS, Walker JL (1987) Stressors and symptoms predictive of distress in farmers. Fam Relat 36:374378. https://doi.org/10.2307/584486

Wilhite DA, Sivakumar MVK, Pulwarty R (2014) Managing drought risk in a changing climate: the role of national drought policy weather and climate. Extremes 3:4-13. https://doi.org/10.1016/j.wace.2014. 01.002 
Wilkinson E, Weingärtner L, Choularton R, Bailey M, Todd M, Kniveton D, Venton CC (2018) Forecasting hazards, averting disasters: Implementing forecast-based early action at scale. Overseas Development Institute

World Food Program (WFP) (2019) Forecast-based Financing (FbF): Anticipatory actions for food security. https://www.preventionweb.net/publications/view/65672

World Meteorological Organization (WMO), Global Water Partnership (GWP). (2016). Handbook of Drought Indicators and Indices, Geneva

Publisher's Note Springer Nature remains neutral with regard to jurisdictional claims in published maps and institutional affiliations. 